\title{
Serotonin Reuptake Inhibitors and Serotonin Transporter Genotype Modulate Performance Monitoring Functions But Not Their Electrophysiological Correlates
}

\author{
๑DAdrian G. Fischer, ${ }^{1,2}$-Tanja Endrass, ${ }^{1}$ Martin Reuter, ${ }^{3}$ Christian Kubisch, ${ }^{4,5}$ and ${ }^{\oplus}$ Markus Ullsperger ${ }^{1,2,6,7}$ \\ ${ }^{1}$ Otto-von-Guericke University, Institute of Psychology, D-39106 Magdeburg, Germany, ${ }^{2}$ Max Planck Institute for Neurological Research, D-50866 Cologne, \\ Germany, ${ }^{3}$ Department of Psychology, University of Bonn, D-53111 Bonn, Germany, ${ }^{4}$ Institute of Human Genetics, University of Ulm, D-89081 Ulm, \\ Germany, ${ }^{5}$ University Medical Center Hamburg-Eppendorf, Institute of Human Genetics, D-20246 Hamburg, Germany, ${ }^{6}$ Radboud University, Donders \\ Institute for Brain, Cognition and Behaviour, 6525 Nijmegen, The Netherlands, and ${ }^{7}$ Center for Behavioral Brain Sciences, D-39106 Magdeburg, Germany
}

\begin{abstract}
Serotonin (5-HT) has been hypothesized to be implicated in performance monitoring by promoting behavioral inhibition in the face of aversive events. However, it is unclear whether this is restricted to external (punishment) or includes internal (response errors) events. The aim of the current study was to test whether higher 5-HT levels instigate inhibition specifically in the face of errors, measured as post-error slowing (PES), and whether this is represented in electrophysiological correlates of error processing, namely error-related negativity (ERN) and positivity. Therefore, from a large sample of human subjects $(n=878)$, two extreme groups were formed regarding hypothesized high and low 5-HT transporter (5-HTT) expression based on 5-HTTLPR and two additional single nucleotide polymorphisms (rs25531, rs25532). Seventeen higher (LL) and 15 lower (SS) expressing Caucasian subjects were administered the selective serotonin reuptake inhibitor (SSRI) citalopram $(10 \mathrm{mg})$ intravenously in a double-blind crossover design. We found pharmacogenetic evidence for a role of 5-HT in mediating PES: SSRI administration increased PES in both genetic groups, and SS subjects displayed higher PES. These effects were absent on post-conflict slowing. However, ERN and error positivity were unaffected by pharmacogenetic factors, but ERN was decoupled from behavioral adaptation by SSRI administration in the LL group. Thus, pharmacogenetic evidence suggests that increased 5-HT levels lead to behavioral inhibition in the context of internal aversive events, but electrophysiological correlates of performance monitoring appear unrelated to the 5-HT system. Therefore, our findings are consistent with theories suggesting that 5-HT mediates the link between aversive processing and inhibition.
\end{abstract}

Key words: serotonin; 5-HTTLPR; citalopram; EEG; performance monitoring

\section{Introduction}

Serotonin (5-HT) has been implicated in the modulation of diverse neurocognitive functions (Lucki, 1998), and considerable attention has been paid to its role in behavioral inhibition and processing of aversive events. It has been reported repeatedly that, in the face of expected punishment, a reduction of 5-HT levels leads to a disinhibition of behavior (Soubrié, 1986; Crockett et al., 2009) such that 5-HT facilitates avoidance of detrimental actions. Such functions are controlled by a performance monitoring network, yet neural evidence for serotonergic involvement in these abilities is sparse.

\footnotetext{
Received Dec. 17, 2014; revised April 14, 2015; accepted April 18, 2015.

Author contributions: A.G.F. and M.U. designed research; A.G.F. and M.U. performed research; A.G.F., T.E., and M.U. analyzed data; A.G.F., T.E., C.K., M.R., and M.U. wrote the paper.

This work was supported by German Ministry of Education and Research Grant 01 GW0722 and German Research Foundation Collaborative Research Centre 779 A 12 (M.U.). We thank Ingrid Goebel and Christian Montag for genotyping, Gerhard Jocham and Theo 0. J. Gründler for fruitful discussions on the presented data, Alexander Waite for proofreading, and Sabrina Döring for her support with data collection.

All authors declare no conflict of interest.

Correspondence should be addressed to Adrian Fischer, Institute of Physiology II Otto von Guericke University, D-39106 Magdeburg, Germany. E-mail: adrian.fischer@ovgu.de.

DOI:10.1523/JNEUROSCI.5124-14.2015

Copyright $\odot 2015$ the authors $\quad 0270-6474 / 15 / 358181-10 \$ 15.00 / 0$
}

The error-related negativity (ERN) and error positivity are EEG potentials thought to reflect early detection and evaluation of evidence for an erroneous response by a performance monitoring network originating in the anterior midcingulate cortex (aMCC; Steinhauser and Yeung, 2010; Ullsperger et al., 2014). After errors, subjects usually slow down their responses and increase their accuracy, a phenomenon known as post-error slowing (PES; Rabbitt, 1966). Single-trial ERN amplitudes have been shown to covary with the amount of slowing induced by errors, suggesting a direct link between error detection and adaptive implementation (Debener et al., 2005). Furthermore, after response conflict, subjects also show reaction slowing, which has been termed post-conflict slowing (PCS; Ullsperger et al., 2005; Verguts et al., 2011). Although PES involves the evaluation of a subjectively aversive event, this is not the case for PCS.

It is currently unclear whether 5-HT-mediated inhibition relies on this performance monitoring network or whether it is mediated in other ways, possibly subcortically. The main approach to study effects of neuromodulatory systems on human behavior are either pharmacological or genetic association studies, both of which have yielded mixed results. Some genetic studies suggest that higher 5-HT levels caused by a polymorphism 
(5-HTTLPR) at the 5-HT transporter (5-HTT) gene (SLC6A4) covary with increased neuronal performance monitoring indices, such as the ERN (Fallgatter et al., 2004), which then may lead to increased inhibition (Holmes et al., 2010); however, data are inconsistent (Olvet et al., 2010). Conversely, pharmacological challenges within the 5 -HT system are complicated by the considerable degree of individual genetic variance (Veenstra-VanderWeele et al., 2000). Thus, well controlled pharmacogenetic studies are highly desirable to elucidate the role of 5-HT in performance monitoring functions.

The aim of the current study was to systematically examine effects of an acute selective pharmacological challenge and genetic variations of the 5-HT system on PES, PCS, and the electrophysiological correlates of error processing, including the single-trial coupling between ERN and PES. We used an acute blockade of 5-HTTs via the intravenous application of a selective serotonin reuptake inhibitor (SSRI) in a double-blind crossover design in human subjects. The genetic background was controlled for by an extreme group approach: from a large sample of genotyped Caucasian subjects $(n=878)$, two groups based on estimated highest (LL; $n=17$ ) and lowest (SS; $n=15$ ) 5-HTT expression were selected (Hu et al., 2006). We hypothesized increased PES (Crockett et al., 2012) and not PCS in S allele carriers, because PES involves evaluation of subjectively aversive events (Boureau and Dayan, 2011). Because SSRIs increase extracellular 5-HT akin to the hypothesized difference between $\mathrm{S}$ and $\mathrm{L}$ allele carriers (Murphy et al., 2008), we furthermore expected increased PES after drug administration. If this effect is mediated via increased performance monitoring activity in the aMCC, accompanying increases in ERN and error positivity and/or coupling of these potentials and following behavioral adaptation would be expected. In contrast, differential modulation and decoupling of error-related potentials and PES would indicate 5-HT-independent routes of the error signal to aMCC-based performance monitoring and post-error motor inhibition.

\section{Materials and Methods}

Participants. Of 878 subjects that had been genotyped for 5-HTTLPR polymorphisms, homozygous $\mathrm{S}$ and L Caucasian subjects were invited to participate in the current study. Thirty-four subjects ( 23 females) were included after a second genotype analysis for rs25531 and rs25532 had been performed for LL subjects (see below). Exclusion criteria were any reported history of psychiatric or neurological disorders, drug abuse, more than moderate alcohol ( $>24$ units/week) or nicotine (more than four cigarettes per day) consumption, and age $<18$ or $>35$ years. Pregnancy was ruled out by measuring human chorionic gonadotropin- $\beta$ $(<0.1 \mathrm{U} / \mathrm{L})$ in blood samples from female subjects $2 \mathrm{~d}$ before each test session to exclude possible fetal risks. The drug was well tolerated, but one subject experienced side effects (nausea and vomiting) and was excluded from the study. Another subject was excluded during the first (placebo) test session because of an inability to follow task instructions. Thus, the final sample consists of $17 \mathrm{LL}$ and 15 SS subjects. For one subject, EEG recording failed during one session and is thus excluded from EEG analysis. All procedures were conducted in accordance with the principles of the Declaration of Helsinki, and the study has been approved by the ethics committee of the Medical Faculty of the University of Cologne (Cologne, Germany).

Genotyping. Genotyping was performed in a two-step sequence. First, of a database of already genotyped subjects $(n=878)$, only homozygous $\mathrm{L}(n=278)$ and $\mathrm{S}(n=156)$ allele carriers were invited to participate in the pharmacological study. This sample included 444 LS carriers and thus was in Hardy-Weinberg equilibrium ( $p=0.354$ for violation). Genotyping was done using automated purification of genomic DNA conducted by means of the MagNA Pure LC System using a commercial extraction kit (MagNA Pure LC DNA isolation kit; Roche Diagnostics). The 5-HTT region was amplified by PCR (Mastercycler). Primer se- quences were $5^{\prime}$-TCCTCCGCTTTGGCGCCTCTTCC-3' and 5' -TGGG GGTTGCAGGGGAGATCCTG-3'. After an initial denaturation for 6 min at $94^{\circ} \mathrm{C}, 37$ cycles of denaturing at $94^{\circ} \mathrm{C}$ for $30 \mathrm{~s}$, annealing at $64^{\circ} \mathrm{C}$ for $1.5 \mathrm{~min}$, and extension at $72^{\circ} \mathrm{C}$ for $1 \mathrm{~min}$ were followed by a final extension at $72^{\circ} \mathrm{C}$ for $5 \mathrm{~min}$. PCR amplification was performed in a final volume of $25 \mu \mathrm{l}$ consisting of $50 \mathrm{ng}$ of genomic DNA, $0.2 \mathrm{~mm}$ of each deoxyribonucleotide, $0.5 \mu \mathrm{M}$ sense and antisense primers, $2.5 \mathrm{~mm} \mathrm{MgCl}{ }_{2}$, $5.3 \%$ dimethyl sulfoxide, $1 \mathrm{U}$ of Diamond Taq polymerase (Eurogentec), and the buffer of the enzyme supplier. For genotyping, samples were loaded onto a $1.6 \%$ agarose gel in a tris-borate-EDTA solution, run for $1 \mathrm{~h} 20 \mathrm{~min}$ at $170 \mathrm{~V}$, and visualized by etidiumbromide under UV light. Samples were visualized and genotyped by at least two independent raters.

A possible problem of studies on the 5-HTTLPR is the presence of two additional single nucleotide polymorphisms (SNPs) that modulate 5-HTT expression on top of the 5-HTTLPR repeat polymorphism. rs25531 $(A>G)$ and rs25532 $(C>T)$ have been identified and, when not controlled for, can lead to 5-HTT expression levels for the L allele similar to those seen for the $\mathrm{S}$ allele (Hu et al., 2006; Wendland et al., 2008). Therefore, to maximize hypothesized group differences in 5-HTT expression, we analyzed these two additional SNPs in all $\mathrm{L} / \mathrm{L}$ allele carriers and excluded low expressing genotypes. This was done by direct sequencing of similarly obtained PCR products as mentioned above. After enzymatic purification with exonuclease I and alkaline phosphatase with both amplification primers, sequences were analyzed using SeqMan DNAStar software (Lasergene). L/L subjects who were not homozygous for both higher expressing forms at rs25531 (A) and rs25532 (C) were excluded; thus, the LL group comprises 17 carriers of the in vitro highest expressing $\mathrm{L}_{\mathrm{AC}} / \mathrm{L}_{\mathrm{AC}}$ genotype (Wendland et al., 2008), and the SS group comprises 15 homozygous carriers of the $S$ allele (Fig. $1 A$ ).

Study procedure and data acquisition. When arriving at the laboratory, all participants completed a clinical interview with the physician in charge, filled in baseline questionnaires (Table 1), and completed visual analog scales (VASs; Bond and Lader, 1974) to asses mood changes. Thereafter, in double-blind manner, either $10 \mathrm{mg}$ of citalopram (Cipramil) diluted in saline $(250 \mathrm{ml})$ or saline alone were administered intravenously over a period of $30 \mathrm{~min}$ (Fig. $1 \mathrm{~B}$ ). The order of administration was counterbalanced. Plasma levels of intravenous citalopram have been shown to remain constant over $\sim 4 \mathrm{~h}$ (Lotrich et al., 2004). On average, subjects performed the task $\sim 85 \mathrm{~min}$ after completion of the infusion (range, 50-125 $\mathrm{min}$ ), which depended on the time necessary to mount EEG caps and execute other tasks. After the infusion was completed, elastic EEG caps (Easycap) with $60 \mathrm{Ag} / \mathrm{AgCl}$ sintered electrodes were mounted in the extended 10-20 system with impedances kept below 5 $\mathrm{k} \Omega$. Data were recorded continuously at a $500 \mathrm{~Hz}$ sampling rate with BrainAmp MR plus amplifiers (Brain Products) and analyzed offline using EEGLAB 12.0 (Delorme and Makeig, 2004) and custom code written in MATLAB 2012b (MathWorks). Electrodes at the left and right outer canthus and above and below the left eye captured eye movements. The ground electrode was positioned at F2; data were online referenced to $\mathrm{CPz}$ and offline re-referenced to common average. The EEG task was performed while subjects were seated in a dimly lit, acoustically and electromagnetically shielded chamber. Additional other tasks were performed, and data of these will be reported elsewhere. Test sessions were separated by at least $7 \mathrm{~d}$ to allow complete washout of the drug, and all female subjects were reinvited for the second session at the same time point in their menstrual cycles as the first session had taken place (i.e., following multiples of 25-31 d) to reduce hormonal fluctuations.

Flanker task. A speeded version of the Eriksen flanker task was used. Subjects had to respond in accordance with the direction of a centrally presented arrow (target) and to ignore four flanking arrows (flankers) that appeared earlier on the screen with a stimulus onset asynchrony of $80 \mathrm{~ms}$ (Fig. 1C). All stimuli stayed thereafter together on screen for $30 \mathrm{~ms}$. On congruent trials, central and flanking arrows pointed to the same direction, whereas on incongruent trials, both pointed into different directions, inducing the tendency to respond to the direction of the flanker. Subjects were instructed to respond as fast and accurately as possible. A random intertrial interval (ITI) was used that varied between 1100 and 2000 ms. Every 100 trials, subjects received written feedback on screen 
A

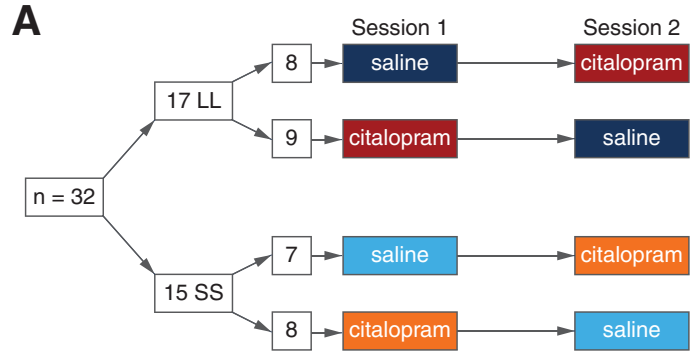

B

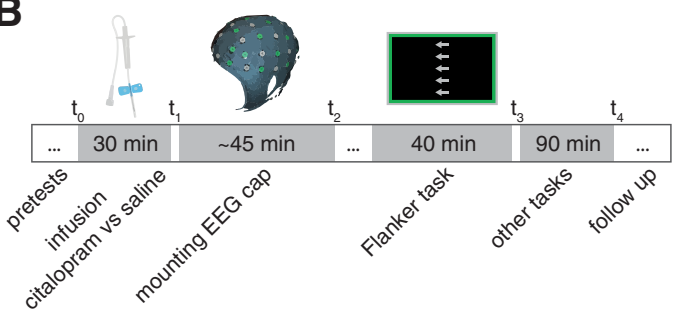

C

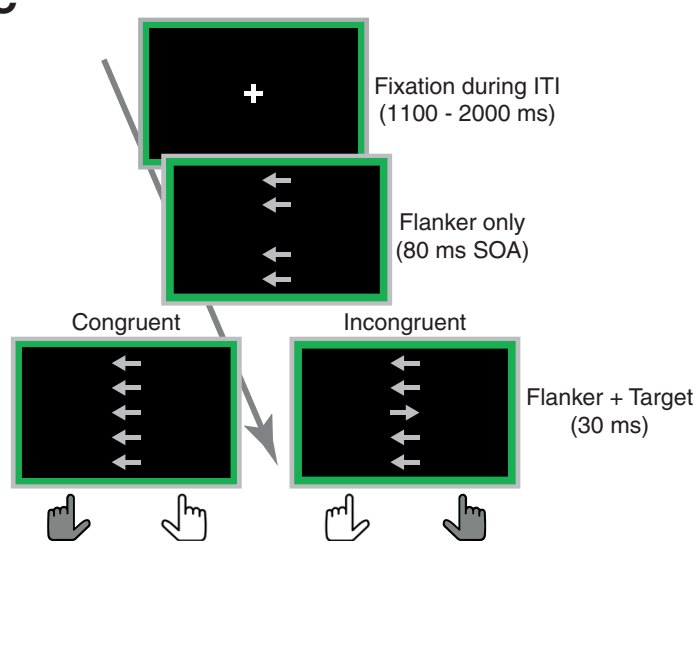

Figure 1. Study design and task structure. $A, B$, Study design and time schedule of drug administration and task conduction. $C$, The timing of the flanker task with congruent and incongruent trials shown separately. SOA, Stimulus onset asynchrony.

\section{Table 1. Demographics and characteristics of the sample}

\begin{tabular}{lllr}
\hline & $\mathrm{LL}(n=17)$ & $\mathrm{SS}(n=15)$ & $p$ for difference \\
\hline Genetics & & & \\
5-HTTLPR & Homozygous long & Homozygous short & \\
rs25531 & $\mathrm{A} / \mathrm{A}$ & & \\
rs25532 & $\mathrm{C} / \mathrm{C}$ & & \\
Demographics & & & \\
$\quad$ Gender (females/males) & $12 / 5$ & $10 / 5$ & \\
Age & $23.8 \pm 0.5$ & $23.9 \pm 0.9$ & 0.920 \\
Weight & $67.8 \pm 2.1$ & $65.7 \pm 0.7$ & 0.518 \\
Verbal IQ & $105.8 \pm 10.1$ & $110.8 \pm 9.0$ & 0.154 \\
Questionnaires & & & \\
BDI-II & $2.85 \pm 0.7$ & $4.03 \pm 0.8$ & 0.300 \\
EPQ-RS neuroticism & $2.94 \pm 0.61$ & $4.73 \pm 0.67$ & 0.056 \\
EPQ-RS psychoticism & $2.59 \pm 0.33$ & $3.2 \pm 0.47$ & 0.288 \\
EPQ-RS extraversion & $9.24 \pm 0.71$ & $8.07 \pm 0.87$ & 0.302 \\
EPQ-RS lie scale & $2.76 \pm 0.50$ & $0.4 \pm 0.13$ & $<0.001$ \\
BIS-11 total & $62.3 \pm 2.2$ & $65.4 \pm 2.1$ & 0.306 \\
BIS attentional & $15.6 \pm 0.6$ & $16.4 \pm 0.7$ & 0.410 \\
BIS motor & $23.5 \pm 0.8$ & $24.1 \pm 0.7$ & 0.544 \\
BIS nonplanning & $23.2 \pm 1.4$ & $25.5 \pm 1$ & 0.187 \\
\hline
\end{tabular}

Group LL included only the high expressing homozygous $\mathrm{L}_{\mathrm{AC}}$ genotype; group $\mathrm{SS}$ included $\mathrm{C}$ and $\mathrm{T}$ variants at rs25532. Groups did not differ with regard to demographics, $I Q$, and baseline depression scores. A significant difference was observed on the lie scale of the EPQ-RS, indicating higher scores of social desirability in the LL group. Additionally, a trend toward higher neuroticism scores was seen in group SS, which is in accordance with previous studies (Schinka et al., 2004). Impulsiveness measured with the BIS-11 did not show group differences. Values represent mean \pm SE. BDI, Beck Depression Inventory; EPQ-RS, Eysenck Personality Questionnaire Revised Short Scale; BIS-11, Barratt Impulsiveness Scale.

about their performance and whether they should speed up their responses. Subjects were told to speed up their responses if the number of errors committed in the incongruent condition was below 20\%. Additionally, the screen was bordered by a colored frame that encouraged subjects to speed up their responses by changing the color from green to red with a delay of 12 trials when they did not commit enough errors. Each subject completed 492 trials, of which half were incongruent. The number of switches from one required response direction to the other, the total number of required responses with the left or right hand in congruent and incongruent condition, and the trial sequence between congruent and incongruent trials were exactly counterbalanced. Before the task began, all subjects completed 21 training trials on each test day.

After each session, subjects had to indicate whether they got angry when committing an error on a scale from 1 (not at all) to 10 (very).
Average scores were $6.7 \pm 0.3$, suggesting that subjects experienced errors as aversive, and reports were not different between genetic or drug conditions [mixed linear model (MLM), all $p$ values $>0.70$ ].

EEG analysis. The signal was bandpass filtered from 0.5 to $42 \mathrm{~Hz}$, and epochs spanning from $2 \mathrm{~s}$ before to $1.5 \mathrm{~s}$ after response onset were extracted. Erroneous and correct trials were corrected separately for artifacts and epochs that contained deviations $>5$ SDs of the mean probability distribution of each condition were automatically rejected. This was done so not to confuse the sometimes very high single-trial ERN amplitudes with artifacts, and no more than $5 \%$ of the trials in each condition were removed. Epoched data were demeaned and submitted to adaptive mixture independent component analysis (Palmer et al., 2012). Independent components reflecting uniform artifacts, such as eyeblinks, were removed from the data, and baseline correction from 300 to $100 \mathrm{~ms}$ before response onset was applied. Average and grand-average waveforms were then calculated, and event-related potential (ERP) data were measured as described in the corresponding results.

To establish the relationship between early correlates of error processing and PES, multiple robust single-trial regression analysis was used (Cohen and Cavanagh, 2011; Fischer and Ullsperger, 2013; Ullsperger et al., 2014). The regression model used the reaction time (RT) of the following trials for all error trials as the dependent variable, whereas EEG activity and following congruency were used as predictor variables including their interaction. Here, all trials in which subjects corrected their response with another button press were excluded. Single-trial data were smoothed with a running average of $10 \mathrm{~ms}$ before and after each data point and calculated for each data point between -250 and $500 \mathrm{~ms}$ surrounding the response at electrode FCz. Robust regression coefficients were scaled by their SDs and are thus comparable across subjects. We used a cluster-based permutation test to correct for multiple comparisons in the time window of interest $(0-500 \mathrm{~ms})$ by randomly multiplying regression weights over subjects with -1 in 5000 iterations. The resulting distribution of the highest sums of $t$ values within resulting clusters of significant effects (threshold $\alpha=0.025$ ) found per iteration were then used to determine $p$ values for the observed effects (Maris and Oostenveld, 2007).

Statistical analyses. MLMs were used to test main effects of factors drug, genotype, and their interactions (Gueorguieva and Krystal, 2004) if not stated otherwise. An additional factor coding the current session (first or second) was introduced to account for training effects attributable to task repetition and the previously reported possible dependence of serotonergic drug effects on order of administration (Murphy et al., 2002). Thus, our main analysis consists of an MLM for the comparison of 
PES versus PCS behaviorally, which includes factors genotype, drug, session, and type of slowing (PES or PCS). Two separate MLM analyses for the EEG data were set up, including the factors genotype, medication, session, and correctness for analysis of response-related ERP amplitudes. The single-trial coupling between ERN amplitude and PES was subsequently analyzed in an MLM with the factors genotype, drug, and session. Additional control analyses were run to ensure the presence of expected task effects, and some more exploratory results are reported as described in the corresponding results for completion. A compound symmetric covariance structure was chosen because it led to best model fits. Analyses were calculated using SPSS version 22 (IBM), and interaction effects were further analyzed by post hoc contrasts of estimated marginal means applying Bonferroni's correction implemented in SPSS.

Unspecific drug effects and control analyses. At the end of each session, subjects filled out questionnaires and VASs again and completed a trailmaking task. This task served as a control to exclude detrimental effects of citalopram on visuomotor coordination, and different versions were used in the first and second test sessions. Citalopram did not prolong the time needed for completion (citalopram, $59 \pm 2 \mathrm{~ms}$; saline, $58 \pm 2 \mathrm{~ms}$; MLM, $\left.F_{(1,32)}<1, p=0.59\right)$, and neither were genetic group differences observed $\left(F_{(1,32)}<1, p=0.44\right)$.

Heart rate and blood pressure were measured immediately before the intravenous cannula was placed $\left(t_{0}\right)$, when the infusion was completed $\left(t_{1}\right)$, and three times thereafter $\left(t_{2}-t_{4}\right)$. Analysis of these data showed a small but robust increase of peripheral mean arterial pressure by citalopram compared with saline (average of $4 \mathrm{mmHg}$ ) at $t_{3}$ and $t_{4}$ (both $p<$ 0.001 ), whereas heart rates remained unchanged, matching 5 -HTs physiologic characteristics (Veenstra-VanderWeele et al., 2000). Additionally, no difference at baseline $\left(t_{0}\right)$ was seen $(p=0.93)$.

VASs were used to assess differences in self-reported mood changes and examined the factors calmness, alertness, and contentedness (Bond and Lader, 1974). We then compared the differences in changes of selfreports between baseline level $\left(t_{0}\right)$ and after the session $\left(t_{4}\right)$ between citalopram and saline conditions in an MLM analysis. We observed a trend for decreased calmness by citalopram administration $\left(F_{(1,32)}=\right.$ $3.30, p=0.079)$ and no effects for the other two factors ( $p$ values $>0.20)$. Exploratory post hoc contrasts showed that the effect on calmness was numerically larger in the SS group (change, $-0.81 \pm 0.48 \mathrm{~cm}, F_{(1,32)}=$ $2.79, p=0.104$ ) than the LL group (change, $-0.39 \pm 0.45 \mathrm{~cm}, F_{(1,32)}=$ $0.76, p=0.390$ ), yet no significant interactions between genotype and drug were observed for any item ( $p$ values $>0.50$ ).

The state part of the state-trait anxiety index (STAI; Spielberger et al., 1983) was used to assess differences in anxiety. Changes induced by the drug were obtained by subtracting baseline levels before each test session from the results attained at follow-up. MLM analysis of these scores showed a trend toward larger pre-post differences in the saline condition $\left(F_{(1,32)}=3.39, p=0.075\right)$, which was attributable to a decrease in scores seen in the saline condition $(\Delta \mathrm{STAI}=-1.4 \pm 0.7$ points, $-2.6 \pm 2 \%$ decrease relative to baseline), whereas scores remained constant under citalopram $(\Delta$ STAI $=0.3 \pm 0.7$ points, $1.5 \pm 2 \%$ increase relative to baseline). Neither the trend-level drug effect for calmness nor STAI scores correlated with drug effects on the variables of interest of PES, ERN, and error positivity (all $p$ values $>0.18$ ).

In summary, these data indicate that successful drug administration and the observed trends are in accordance with effects of acute SSRI administration that may increase restlessness or anxiety initially (Burghardt and Bauer, 2013), possibly mediated by corelease of other transmitters (Fischer et al., 2015), yet no severe side effects are seen such that unspecific drug-related confounds could be ruled out.

\section{Results}

\section{Behavioral effects}

Main analysis

We calculated PES by subtracting median RTs on correct trials after errors from those that did not follow errors (Fig. 2A). Trials that represented double errors (i.e., were preceded or followed by another error) were excluded. Additionally, we performed the same calculation for trials that followed incongruent events, which are also known to induce slowing on the following trial (Ullsperger et al., 2005; Verguts et al., 2011) and submitted both to MLM analysis with factor type of slowing (PES or PCS). This analysis revealed a main effect for factor type of slowing, indicating higher slowing after incongruent events (18 $\pm 2 \mathrm{~ms})$ compared with errors $(10 \pm 2 \mathrm{~ms})$. Furthermore, significant interactions for type of slowing with $\operatorname{drug}\left(F_{(1,96)}=7.8, p=\right.$ $0.006)$ and genotype $\left(F_{(1,32)}=4.2, p=0.043\right)$ were seen. Post hoc tests confirmed a significant drug effect on PES in which citalopram increased slowing by $9 \pm 3 \mathrm{~ms}\left(F_{(1,96)}=9.1, p=0.003\right)$, whereas it led to a nonsignificant decrease of PCS $(\Delta \mathrm{RT},-3 \pm 3$ $\left.\mathrm{ms}, F_{(1,96)}=0.9, p=0.35\right)$. Subjects carrying the SS genotype showed higher PES ( $15 \pm 3 \mathrm{~ms}$ ) than subjects with LL genotype $\left(5 \pm 3 \mathrm{~ms}, F_{(1,55.8)}=5.0, p=0.029\right)$. No difference between genetic groups was seen for PCS $\left(\Delta \mathrm{RT}, 0.6 \pm 4 \mathrm{~ms}, F_{(1,96)}<1, p=\right.$ 0.88 ). The drug effect did not depend on the genotype (interaction of genotype $\times$ drug and genotype $\times$ drug $\times$ type of slowing, both $F<1$ and $p>0.5$ ). These results indicate that slowing induced by errors but not conflict was specifically increased by citalopram and that SS subjects with presumably higher 5-HTT expression also display more slowing.

\section{Control analyses}

A confirmatory MLM analysis of overall median RTs in the task showed trends for higher RTs under citalopram $(360 \pm 3 \mathrm{~ms})$ than the saline condition $\left(354 \pm 3 \mathrm{~ms}, F_{(1,32)}=3.3, p=0.077\right)$ and toward faster RTs for subjects with genotype LL $(351 \pm 4 \mathrm{~ms})$ than SS $\left(362 \pm 5 \mathrm{~ms}, F_{(1,32)}=\right.$ $3.45, p=0.072$ ). Neither the total number of errors (Fig. $2 B$ ) nor the number of errors on incompatible trials was modulated by genotype or drug (MLM, all $p>0.20$ ). Comparable with other studies, subjects in our task were slower in the more difficult incongruent trials $(\Delta \mathrm{RT}, 76 \pm 2 \mathrm{~ms}$, $\left.p<10^{-10}\right)$. Furthermore, subjects responded faster when they made an erroneous response $\left(\Delta \mathrm{RT},-90 \pm 2 \mathrm{~ms}, p<10^{-10}\right)$. None of these factors interacted with drug or genotype (all $p>0.29)$.

\section{Exploratory analyses}

Across individuals, higher PES (but not PCS) correlated positively with a post-error increase in accuracy (PIA; Danielmeier et al., 2011) in both the 


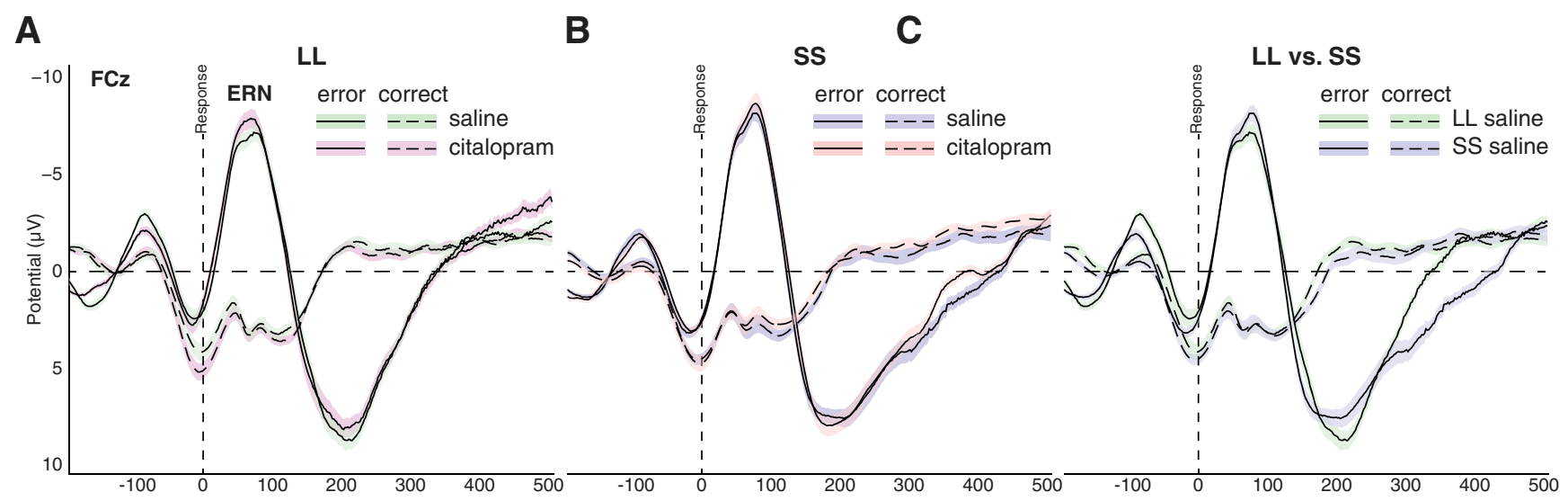

D

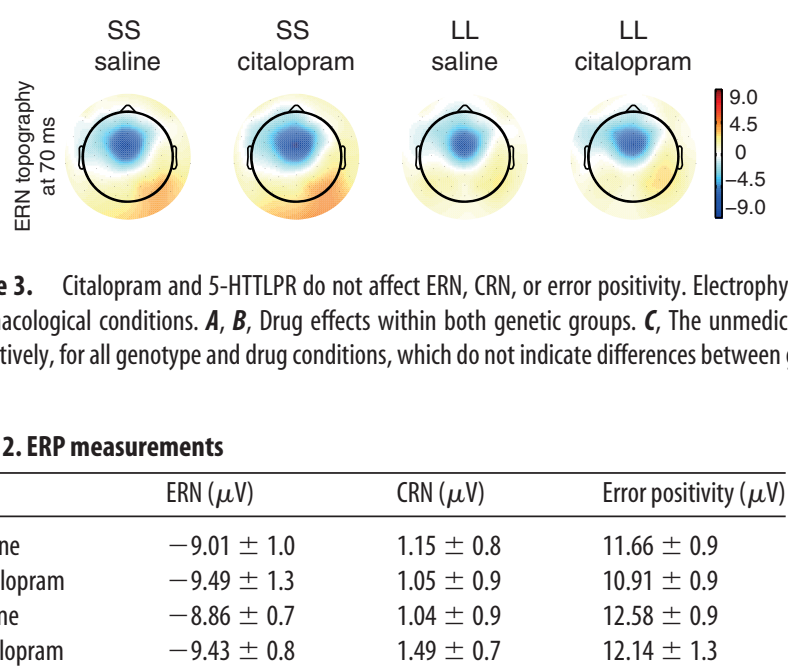

ERN and CRN were measured as the individual average minima between 0 and $100 \mathrm{~ms}$ after response onset at electrode $\mathrm{FCZ}( \pm \mathrm{SEM})$. The error positivity was quantified as the individual average maxima between 100 and 350 ms after response onset at electrode C $\mathrm{Z}$. Neither measure was modulated by acute SSRI administration, 5 -HTTLPR genotype, or their interaction.

saline $(r=0.45, p=0.009)$ and citalopram $(r=0.48, p=0.005)$ conditions (PCS, all $p$ values $>0.18$ ), suggesting that PES provided time for more task-specific post-error adjustments (Danielmeier and Ullsperger, 2011). However, accuracy after errors was not affected by any 5 -HTrelated factor (all $p$ values $>0.1$ ). This can in part be explained by the high variability (range, 1-21) and the low average number of double errors $(6 \pm 0.62)$, rendering this an insensitive measure. Additionally, we found no 5-HT-related effects on post-error reduction of interference, PIA itself, or the conflict-adaptation effect (all $p$ values $>0.1$ for drug, genotype, and their interaction; Gratton et al., 1992).

\section{Main EEG analysis}

After artifact correction, on average, 43 incompatible error trials (range, 26-52) per subject remained after double errors were excluded. ERN and correct-related negativity (CRN) amplitudes were measured as the negative peak between 0 and $100 \mathrm{~ms}$ at electrode $\mathrm{FCz}$ akin to the first study reporting an effect of 5-HTTLPR on ERN amplitudes (Fallgatter et al., 2004; Fig. 3). MLM analysis confirmed a highly significant effect for factor trial type (error, correct) on EEG amplitudes (error $\Delta \mu \mathrm{V},-10.5 \pm$ $\left.0.5, F_{(1,81)}=445, p<10^{-10}\right)$, but neither were effects for factors drug and genotype nor their interaction observed (all $F$ values $<0.1, p$ values $>0.75)$. Exploratory contrasts within error trials revealed no effect for $\operatorname{drug}\left(F_{(1,31)}<1, p=0.37\right)$ or genotype $\left(F_{(1,31)}<1, p=0.96\right)$ and no interaction $\left(F_{(1,31)}<1, p=0.90\right.$; for exact values, see Table 2$)$, and neither were significant effects
$\mathbf{E}$

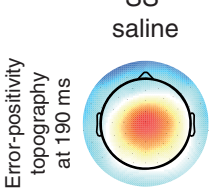

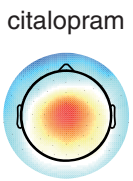

LL
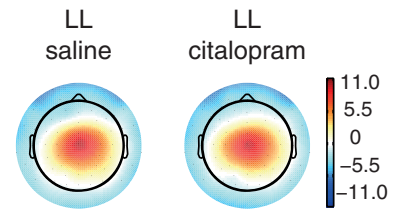

siological indices of performance monitoring were not significantly different between genetic and pharmacological conditions. A, B, Drug effects within both genetic groups. C, The unmedicated genetic comparison. D, E, Scalp topographies at peak latencies for ERN and error positivity, respectively, for all genotype and drug conditions, which do not indicate differences between genotypes or medication states. Shaded plots and error bars reflect SEM.

observed on correct trials for factors drug $\left(F_{(1,31)}<1, p=0.42\right)$, genotype $\left(F_{(1,31)}<1, p=0.92\right)$, or their interaction $\left(F_{(1,31)}<1\right.$, $p=0.35)$. Amplitudes of the error positivity, measured as the maximum peak between 100 and $350 \mathrm{~ms}$ at $\mathrm{Cz}$, where amplitudes were highest, were again not modulated by genotype $\left(F_{(1,31)}<1\right.$, $p=0.44)$ or $\operatorname{drug}\left(F_{(1,31)}<1, p=0.29\right.$; interaction, $F_{(1,31)}<1, p=$ 0.88 .

Furthermore, ERP peak latencies did not differ depending on any 5-HT-related factor for ERN ( $p$ values $>0.42)$ and error positivity ( $p$ values $>0.65$ ). The variance in ERN latencies was somewhat larger in the LL group in the saline (mean $\pm \mathrm{SD}$ : LL, $61 \pm 21 \mathrm{~ms}$; SS, $66 \pm 16 \mathrm{~ms}$ ) and citalopram (LL, $60 \pm 18 \mathrm{~ms}$; SS, $64 \pm 14 \mathrm{~ms}$ ) conditions.

\section{Single-trial regression results}

Using multiple robust regression analysis of single-trial ERN and following post-error RT, we first sought to establish the link between EEG data and PES across all subjects by testing regression coefficients collapsed over the repeated factor (drug) against zero. This revealed negative covariations in the ERN time window (ERN peak, $34 \mathrm{~ms}$; $t$ test against $0, t_{(30)}=-4.33, p=0.0046$ cluster-based permutation test; Fig. $4 A$ ), indicating that the more negative the ERN on a single-trial level was, the higher the following RT was; this pattern is in accordance with other studies (Debener et al., 2005; Wessel and Ullsperger, 2011). Furthermore, the opposite effect was observed for error positivity amplitudes, in which a positive covariation was observed (error positivity peak, $146 \mathrm{~ms} ; t_{(30)}=3.66, p=0.027$, cluster-based permutation test). This suggests that ERN and error positivity both are sensitive for single-trial variation and adjust subsequent slowing, likely to provide time for adjustment. No significant interaction depending on the congruency of the following trials was found. We then established the effects of drug and genotype by submitting regression coefficients (measured as response-locked minima of regression coefficients between 0 and $100 \mathrm{~ms}$ ) to MLM analysis. This revealed a significant drug $\times$ genotype interaction: for subjects 
A

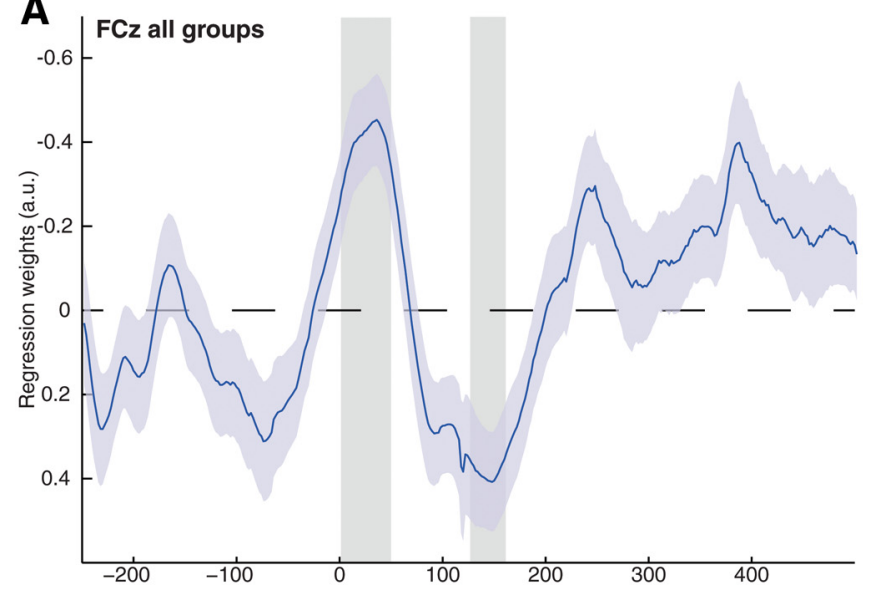

B

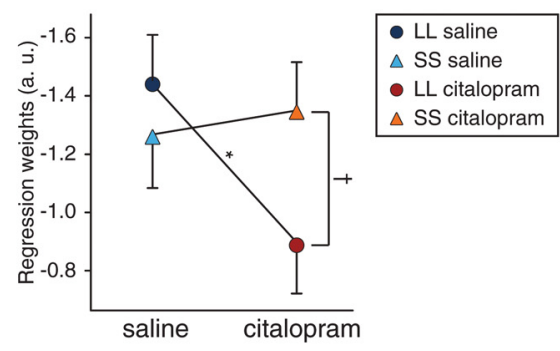

Figure 4. Relationship between ERN, error positivity, and PES via multiple robust regression. $A$, During the time window of the ERN, a significant negative covariation between single-trial EEG in error trials and their respective following RT was observed, indicating more slowing when ERN amplitudes were higher (cluster-based permutation test, $p=0.0046$ ). The opposite pattern is seen in the time window of the error positivity $(p=0.027)$ in which slowing increases when amplitudes become more positive. Data here are collapsed over drug conditions, and gray areas mark significant time windows with $p<0.01$ uncorrected. $\boldsymbol{B}$, A significant decrease in the covariation between single-trial ERN and consecutive slowing was seen for LL ( $p=0.009)$ but not $S S$ ( $p=$ 0.638 ) subjects when comparing saline and drug condition. Shaded plots and error bars reflect SEM.

homozygous for the L allele, citalopram significantly decreased the covariation between ERN and following RT $(\Delta b=-0.55 \pm$ $\left.0.19, F_{(1,31)}=7.82, p=0.009\right)$ which was not observed for subjects homozygous for the $S$ allele $\left(\Delta b=0.09 \pm 0.20, F_{(1,31)}<1\right.$, $p=0.638$; interaction drug $\times$ genotype, $F_{(1,31)}=5.22, p=0.029$; Fig. $4 B)$. No other main effects or interactions were significant (all $p$ values $>0.12$ ), and no drug or genotype effects were observed for the following error-positivity-related covariation that was revealed in the initial analysis (measured as maximum regression coefficients between 100 and $200 \mathrm{~ms}$, all $p$ values $>0.14$ ).

\section{Supporting EEG analyses}

To increase confidence in the reported null effect on ERN amplitudes and decrease the likelihood of a methodological problem in ERP quantification that prevented us from finding a true effect, we report here additional results that were obtained by different ways of ERP quantification, inclusion of more trials, accounting for general subjective amplitude variance, and an analysis of midfrontal theta power.

First, we used the average ERN amplitude in the $20 \mathrm{~ms}$ surrounding the grand-average peak (64 ms) instead of the individual minimum amplitude, which may be a more sensitive measure because it reduces group variance. However, we did not observe a $\operatorname{drug}\left(F_{(1,31)}=1.83, p=0.19\right)$, genotype $\left(F_{(1,31)}<1, p=0.54\right)$, or an interaction $\left(F_{(1,31)}<1, p=0.72\right)$ effect. Although none of the comparisons were significant, the pattern of ERN results resembled those on PES (LL saline, $-6.8 \pm 0.7 \mu \mathrm{V}$ vs SS saline, $-7.6 \pm$ $0.8 \mu \mathrm{V}, p=0.472$ genetic comparison without drug; LL citalopram, $-7.6 \pm 0.7 \mu \mathrm{V}$; SS citalopram, $-8.1 \pm 0.8 \mu \mathrm{V})$. Results were not changed when all errors, instead of only errors on incompatible trials, were included into the analysis.

The choice of baseline can influence results of peak- and average-amplitude measures. Furthermore, baseline amplitudes in response-locked analyses can be confounded by other factors (e.g., RT). Thus, we repeated the analysis by applying a baseline correction to the response-locked data that was derived from the prestimulus activity of each trial ( -300 to $-100 \mathrm{~ms})$ and always fell into the response-stimulus interval. The apparently more sensitive mean ERN measure (54-74 ms) showed no effect of $\operatorname{drug}\left(F_{(1,31)}<1, p=0.44\right)$, genotype $\left(F_{(1,31)}<1, p=0.86\right)$, or their interaction $\left(F_{(1,31)}<1, p=0.93\right)$. Finally, we also normalized measured ERN amplitudes by the average root mean square baseline prestimulus power, which thus should account for possible, especially morphological, intersubject differences. However, neither for minimum ( $p$ values $>0.16$ ) nor mean $(p$ values $>0.2)$ ERN amplitudes were 5-HT-related effects observed.

We also investigated genetic and pharmacological effects on midfrontal theta power. Therefore, we applied current source density transformation (Kayser and Tenke, 2006) to the EEG signal, which was then convolved with a series of complex Morlet wavelets between 3 and $40 \mathrm{~Hz}$ in 37 linear steps using a wavelet width of 4.5 cycles. Prestimulus ( -300 to $-100 \mathrm{~ms}$ ) baseline power was subtracted from each response-locked epoch, and data were thereafter scaled by the average power in the baseline range to reflect multiples of baseline activity. Because power can only be positive and thus noise likely skews results to be larger when trial numbers are lower, the trial numbers between all subjects and across erroneous and correct responses (trials chosen as described above) were reduced to the number of the lowest category (26 trials) by randomly discarding the other trials. Theta power was then derived by collapsing power from 4 to $8 \mathrm{~Hz}$ and measured as the average power from $-100 \mathrm{~ms}$ until $300 \mathrm{~ms}$ around the response at electrodes $\mathrm{FCz}$ and $\mathrm{Cz}$. At both electrodes and within all genotype and drug conditions, theta power was significantly larger on error (FCz: average, $616 \pm 25 \%$ of baseline) compared with correct trials (FCz: average, $284 \pm 19 \%$ of baseline, all $p<10^{-6}$ ). However, we observed neither a genetic or pharmacological nor an interaction effect on midfrontal theta power (all $p$ values for both electrodes $>0.1$ ).

\section{Session effects}

We found that overall RTs were shorter when subjects performed the task for the second time $\left(F_{(1,32)}=9.90, p=0.004\right)$. Furthermore, PES decreased from $16 \mathrm{~ms}$ in the first session to only $4 \mathrm{~ms}$ in the second session $\left(F_{(1,32)}=12.76, p=0.001\right)$. No interactions involving the factors genotype or drug were significant (all $p$ values $>0.19)$. The number of errors was not modulated by factor session $\left(F_{(1,32)}<1, p=0.82\right.$, average $n$ errors for session $1=$ $63.1 \pm 1.9$ and for session $2=63.5 \pm 1.9)$. Also, PCS was not 
significantly reduced in the second session (first session, $20 \pm 2$ $\mathrm{ms}$; second session, $16 \pm 2 \mathrm{~ms} ; F_{(1,32)}=3.33, p=0.078$; interaction type of slowing $\times$ session, $\left.F_{(1,96)}=3.5, p=0.065\right)$. This indicates that subjects increased their performance when they were more acquainted with the task indicated by lower RTs and constant error rates and also seemed to be able to decrease PES but less so PCS. This highlights the importance of accounting for session effects in repeated-measures designs, even for tasks that do not involve learning of task structures. For EEG measures, error positivity $\left(-1.65 \pm 0.71 \mu \mathrm{V}, F_{(1,31)}=10.3, p=0.003\right)$ and $\mathrm{CRN}\left(1.29 \pm 0.49 \mu \mathrm{V}, F_{(1,31)}=10.6, p=0.003\right)$ amplitudes were reduced when the task was performed the second time. No effect of task repetition was observed for ERN amplitudes $\left(F_{(1,31)}<1\right.$, $p=0.61)$. In accordance with the observed PES reduction in the second session, although no ERN reduction was observed, we also found a session effect in that covariation between EEG and $\mathrm{RT}$ was reduced when the task was repeated $(\Delta b=-0.40 \pm 0.14$, $\left.F_{(1,31)}=7.81, p=0.009\right)$.

\section{Discussion}

The aim of this study was to investigate the relationship and specificity of 5-HT to error-related aversive inhibition and its electrophysiological correlates. We found pharmacological and converging genetic evidence that higher 5-HT levels are associated with increased PES, yet no ERP effect was found.

Acute intravenous low-dose SSRI administration led to increased PES across genetic groups without affecting conflictinduced slowing. SSRIs block the 5-HTT, which prevents 5-HT reuptake and leads to increased 5-HT levels in most brain regions as evidenced via microdialysis (Beyer and Cremers, 2008), although one recent study suggests that especially cortical regions may show the opposite effect (Selvaraj et al., 2012). Furthermore, SS subjects displayed higher PES compared with the LL group, which fits well to the notion that this genotype displays higher extracellular 5-HT levels attributable to lower 5-HTT expression, as has been demonstrated in mouse models of 5-HTTLPR (Mathews et al., 2004; Murphy et al., 2008). Although the link between in vitro mRNA 5-HTT expression and in vivo measures of 5-HTT binding (Jedema et al., 2010; Murthy et al., 2010) has been highly debated, many studies report differential responses to perturbations in 5-HT neurotransmission depending on 5-HTTLPR genotype (Roiser et al., 2006; Markus and Firk, 2009). This suggests that, at least in part, genetic factors influence ongoing serotonergic neurotransmission. Thus, the pharmacological effect suggests a positive relationship between 5-HT levels and behavioral adaptation after subjectively aversive events, and this effect is compatible with the observed genetic effect. However, given the difficulty in replicating previous genetic studies (NCINHGRI Working Group on Replication in Association Studies, 2007), the latter finding clearly requires replication in an independent sample.

These data fit well to ideas in which 5-HT mediates behavioral inhibition only in the context of aversive events, likely to prevent the repetition of maladaptive behavior (Dayan and Huys, 2009; Boureau and Dayan, 2011; Cools et al., 2011), whereas it has been noted that serotonergic influences on inhibition are usually minimal when measured in unrewarded contexts in both humans and animals alike (Winstanley, 2011). However, there is an ongoing discussion as to how 5-HT achieves this effect. Some studies suggested that 5-HT mediates the subjective effect of aversive events. This idea is mainly based on genetic evidence in which the 5-HTTLPR S allele has been identified as a risk factor for depres- sion after aversive life events (Caspi et al., 2003) that could be mediated by an overactive aMCC-dependent performance monitoring system (Holmes et al., 2010; Drabant et al., 2012). Supporting this idea, one study by Fallgatter et al. (2004) reported increased ERN amplitudes for $\mathrm{S}$ allele carriers, yet a replication attempt failed (Olvet et al., 2010). Therefore, evidence for a link between the serotonergic system and EEG correlates of errorrelated functions is weak.

Another suggestion is that 5-HT does not mediate the actual effect of aversive events or general behavioral inhibition but rather the link between them both (Dayan and Huys, 2008; Crockett et al., 2009). Crockett et al. (2012) showed that acute dietary tryptophan depletion (ATD), a method that lowers serotonergic neurotransmission, abolished response slowing in the context of punishment predicting stimuli in a reinforced categorization task. ATD also reduced the inhibitory effects of aversive pavlovian cues on instrumental choices and impaired the ability to passively avoid unfavorable stimuli by increasing active responding (Geurts et al., 2013). Furthermore, optogenetic stimulation of serotonergic neurons in mice increased the ability to withhold responding to obtain a primary reward without affecting locomotion (Miyazaki et al., 2014). Additionally, studies investigating serotonergic effects on instrumental choices suggest increased lose-switch behavior associated with the L allele (den Ouden et al., 2013) and increased resilience to negative feedback after high SSRI doses in rats (Bari et al., 2010). These findings appear in line with the observed increase in PES reported here because less deliberation time may lead to less optimal choices. Furthermore, the absence of 5-HT effects on electrophysiological indices of error detection are well compatible with the notion that 5-HT mediates the link between aversive events and inhibition, because these ERPs themselves likely do not reflect this transition into behavioral adaptation.

It should be noted that, although human studies mostly found evidence for a role of 5-HT in promoting inhibition specifically when punishment was expected (Crockett et al., 2012; Geurts et al., 2013) or had to be predicted (Cools et al., 2008; Robinson et al., 2011), electrophysiological (Miyazaki et al., 2012b) and recent optogenetic evidence from rodent studies (Miyazaki et al., 2014) indicate that 5-HT may be involved in inhibition to avoid punishment but also to obtain a reward. Furthermore, interfering with serotonergic signaling of optogenetically targeted raphe neurons decreased behavior that required maintenance of motivation (Liu et al., 2014). Thus, another possible explanation for the main physiologic role of 5-HT may be to increase patiencebefore inhibiting or activating to avoid punishment or achieve a reward (Miyazaki et al., 2012a). Our data are compatible with this proposal of serotonergic functioning because it could be interpreted as an increase in patience to avoid repetition of a mistake accompanying increased 5-HT levels. However, more experiments that specifically orthogonalize aversive and appetitive factors with inhibition and maintenance of activity are highly desirable.

The behavioral effects on PES emerged in the absence of differences in subjective estimates of self-reported affect in response to errors, compatible with other studies (Hariri et al., 2002; Holmes et al., 2010) and in accordance with absence of effects on ERN and error positivity, which are assumed to be sensitive toward the functional significance or salience of an error (Falkenstein et al., 2000). This further suggests that 5-HT mediates inhibitory effects independent of subjective appreciation of errors and possibly the cortical performance monitoring network. Certainly the current study is not sufficiently powerful to finally rule out an association between ERN or error positivity and 
5-HT, which may be found in larger samples. However, it should be noted that, even when very sensitive measures of ERN amplitudes were post hoc explored, neither drug nor genetic effects approached trend levels. Especially the absence of a drug effect in a powerful repeated-measures design with well controlled intravenous drug application and control for the genetic background suggests independence of electrophysiological indices of error processing from the 5-HT system in accordance with other studies using orally applied SSRIs (de Bruijn et al., 2006; Barnes et al., 2013). Additionally, it is unlikely that the drug dose used in the current study was insufficient to induce effects. Even an oral dose of $10 \mathrm{mg}$ of citalopram has been demonstrated to block $>65 \%$ of midbrain 5-HTTs via in vivo single-photon emission computed tomography (Klein et al., 2006), and we observed clear behavioral and cardiovascular effects. Thus, it seems that the neurogenerators giving rise to ERN and error positivity are insensitive to acute pharmacological perturbations and likely genetic variation in the serotonergic system.

One may wonder how the behavioral 5-HT effects then arise. When the link between error detection and translation into behavioral adaptation is investigated more directly, we found differential effects of the drug in both genetic groups. For LL subjects, the strength of coupling between ERN and consecutive RT adjustments is decreased by SSRI administration, but this is not the case for SS subjects. One could speculate that higher SSRI doses may lead to interactive effects for other factors as well, for example, when assuming an inverted U-shaped relationship between 5-HT and efficient functioning (Cano-Colino et al., 2014). The decoupling of behavioral adaptation suggests an independent mechanism that increases behavioral inhibition and does not affect cortical EEG correlates. One may thus speculate that the inhibition is implemented in subcortical structures, of which especially the subthalamic nucleus (STN) seems a likely structure to mediate PES (Cavanagh et al., 2014; Siegert et al., 2014). Furthermore, the STN has long been known to receive strong serotonergic projections from raphe nuclei, in which most of the brain serotonergic neurons reside, and 5-HT injections into the STN increased firing rates (Xiang et al., 2005). At least a subpopulation of likely serotonergic raphe neurons code aversive signals (Nakamura et al., 2008), which may mediate the observed slowing effect.

Finally, the genetic findings of higher PES in the SS group also highlight that, although the $S$ allele may be a risk factor for mood disorders, under certain circumstances, greater behavioral adaptation after mistakes may also be beneficial, because it can serve to decrease the likelihood of repeating a mistake (Homberg and Lesch, 2011). In line with this, we found a robust correlation between PES and the increase of accuracy after errors, suggesting that subjects in our task were more cautious in responding in post-error trials, which effectively kept performance high (Danielmeier and Ullsperger, 2011).

In summary, the current study provides important new evidence for a role of 5-HT in mediating rapid behavioral adaptation after response errors in that higher 5-HT levels appear to increase PES as evidenced by pharmacological effects that are corroborated by converging genetic findings. However, cortical electrophysiological correlates of error processing appear unaffected by serotonergic influences, and the behavioral effect may be mediated subcortically. This provides strong evidence for a role of 5-HT as the link between aversive processing and resulting inhibitory effects. Clearly, more imaging and electrophysiological studies are needed to elucidate the neural mechanisms underly- ing 5-HT-mediated inhibition, especially on the level of brainstem activity and its association to aversive coding.

\section{References}

Bari A, Theobald DE, Caprioli D, Mar AC, Aidoo-Micah A, Dalley JW, Robbins TW (2010) Serotonin modulates sensitivity to reward and negative feedback in a probabilistic reversal learning task in rats. Neuropsychopharmacology 35:1290-1301. CrossRef Medline

Barnes JJM, O'Connell RG, Nandam LS, Dean AJ, Bellgrove MA (2013) Monoaminergic modulation of behavioural and electrophysiological indices of error processing. Psychopharmacology (Berl) 231:379-392. CrossRef

Beyer CE, Cremers TIFH (2008) Do selective serotonin reuptake inhibitors acutely increase frontal cortex levels of serotonin? Eur J Pharmacol 580: 350-354. CrossRef Medline

Bond A, Lader M (1974) The use of analogue scales in rating subjective feelings. Br J Med Psychol 47:211-218. CrossRef

Boureau YL, Dayan P (2011) Opponency revisited: competition and cooperation between dopamine and serotonin. Neuropsychopharmacology 36:74-97. CrossRef Medline

Burghardt NS, Bauer EP (2013) Acute and chronic effects of selective serotonin reuptake inhibitor treatment on fear conditioning: implications for underlying fear circuits. Neuroscience 247:253-272. CrossRef Medline

Cano-Colino M, Almeida R, Gomez-Cabrero D, Artigas F, Compte A (2014) Serotonin regulates performance nonmonotonically in a spatial working memory network. Cereb Cortex 24:2449-2463. CrossRef Medline

Caspi A, Sugden K, Moffitt TE, Taylor A, Craig IW, Harrington H, McClay J, Mill J, Martin J, Braithwaite A, Poulton R (2003) Influence of life stress on depression: moderation by a polymorphism in the 5-HTT gene. Science 301:386-389. CrossRef Medline

Cavanagh JF, Sanguinetti JL, Allen JJB, Sherman SJ, Frank MJ (2014) The subthalamic nucleus contributes to post-error slowing. J Cogn Neurosci 26:2637-2644. CrossRef Medline

Cohen MX, Cavanagh JF (2011) Single-trial regression elucidates the role of prefrontal theta oscillations in response conflict. Front Psychol 2:30. CrossRef Medline

Cools R, Robinson OJ, Sahakian B (2008) Acute tryptophan depletion in healthy volunteers enhances punishment prediction but does not affect reward prediction. Neuropsychopharmacology 33:2291-2299. CrossRef Medline

Cools R, Nakamura K, Daw ND (2011) Serotonin and dopamine: unifying affective, activational, and decision functions. Neuropsychopharmacology 36:98-113. CrossRef Medline

Crockett MJ, Clark L, Robbins TW (2009) Reconciling the role of serotonin in behavioral inhibition and aversion: acute tryptophan depletion abolishes punishment-induced inhibition in humans. J Neurosci 29:1199311999. CrossRef Medline

Crockett MJ, Clark L, Apergis-Schoute AM, Morein-Zamir S, Robbins TW (2012) Serotonin modulates the effects of Pavlovian aversive predictions on response vigor. Neuropsychopharmacology 37:2244-2252. CrossRef Medline

Danielmeier C, Ullsperger M (2011) Post-error adjustments. Front Psychol 2:233. CrossRef Medline

Danielmeier C, Eichele T, Forstmann BU, Tittgemeyer M, Ullsperger M (2011) Posterior medial frontal cortex activity predicts post-error adaptations in task-related visual and motor areas. J Neurosci 31:1780-1789. CrossRef Medline

Dayan P, Huys QJM (2008) Serotonin, inhibition, and negative mood. PLoS Comput Biol 4:e4. CrossRef Medline

Dayan P, Huys QJM (2009) Serotonin in affective control. Annu Rev Neurosci 32:95-126. CrossRef Medline

Debener S, Ullsperger M, Siegel M, Fiehler K, von Cramon DY, Engel AK (2005) Trial-by-trial coupling of concurrent electroencephalogram and functional magnetic resonance imaging identifies the dynamics of performance monitoring. J Neurosci 25:11730-11737. CrossRef Medline

de Bruijn ERA, Sabbe BGC, Hulstijn W, Ruigt GSF, Verkes RJ (2006) Effects of antipsychotic and antidepressant drugs on action monitoring in healthy volunteers. Brain Res 1105:122-129. CrossRef Medline

Delorme A, Makeig S (2004) EEGLAB: an open source toolbox for analysis of single-trial EEG dynamics including independent component analysis. J Neurosci Methods 134:9-21. CrossRef Medline

den Ouden HEM, Daw ND, Fernandez G, Elshout JA, Rijpkema M, Hoog- 
man M, Franke B, Cools R (2013) Dissociable effects of dopamine and serotonin on reversal learning. Neuron 80:1090-1100. CrossRef Medline

Drabant EM, Ramel W, Edge MD, Hyde LW, Kuo JR, Goldin PR, Hariri AR, Gross JJ (2012) Neural mechanisms underlying 5-HTTLPR-related sensitivity to acute stress. Am J Psychiatry 169:397-405. CrossRef Medline

Falkenstein M, Hoormann J, Christ S, Hohnsbein J (2000) ERP components on reaction errors and their functional significance: a tutorial. Biol Psychol 51:87-107. CrossRef Medline

Fallgatter AJ, Herrmann MJ, Roemmler J, Ehlis AC, Wagener A, Heidrich A, Ortega G, Zeng Y, Lesch KP (2004) Allelic variation of serotonin transporter function modulates the brain electrical response for error processing. Neuropsychopharmacology 29:1506-1511. CrossRef Medline

Fischer AG, Ullsperger M (2013) Real and fictive outcomes are processed differently but convergeon a common adaptive mechanism. Neuron 79: 1243-1255. CrossRef Medline

Fischer AG, Jocham G, Ullsperger M (2015) Dual serotonergic signals: a key to understanding paradoxical effects? Trends Cogn Sci 19:21-26. CrossRef Medline

Geurts DEM, Huys QJM, den Ouden HEM, Cools R (2013) Serotonin and aversive pavlovian control of instrumental behavior in humans. J Neurosci 33:18932-18939. CrossRef Medline

Gratton G, Coles MG, Donchin E (1992) Optimizing the use of information: strategic control of activation of responses. J Exp Psychol Gen 121: 480-506. CrossRef Medline

Gueorguieva R, Krystal JH (2004) Move over ANOVA: progress in analyzing repeated-measures data and its reflection in papers published in the Archives of General Psychiatry. Arch Gen Psychiatry 61:310-317. CrossRef Medline

Hariri AR, Mattay VS, Tessitore A, Kolachana B, Fera F, Goldman D, Egan MF, Weinberger DR (2002) Serotonin transporter genetic variation and the response of the human amygdala. Science 297:400-403. CrossRef Medline

Holmes AJ, Bogdan R, Pizzagalli DA (2010) Serotonin transporter genotype and action monitoring dysfunction: a possible substrate underlying increased vulnerability to depression. Neuropsychopharmacology 35: 1186-1197. CrossRef Medline

Homberg JR, Lesch KP (2011) Looking on the bright side of serotonin transporter gene variation. Biol Psychiatry 69:513-519. CrossRef Medline

Hu XZ, Lipsky RH, Zhu G, Akhtar LA, Taubman J, Greenberg BD, Xu K, Arnold PD, Richter MA, Kennedy JL, Murphy DL, Goldman D (2006) Serotonin transporter promoter gain-of-function genotypes are linked to obsessive-compulsive disorder. Am J Hum Genet 78:815-826. CrossRef Medline

Jedema HP, Gianaros PJ, Greer PJ, Kerr DD, Liu S, Higley JD, Suomi SJ, Olsen AS, Porter JN, Lopresti BJ, Hariri AR, Bradberry CW (2010) Cognitive impact of genetic variation of the serotonin transporter in primates is associated with differences in brain morphology rather than serotonin neurotransmission. Mol Psychiatry 15:512-522, 446. CrossRef Medline

Kayser J, Tenke CE (2006) Principal components analysis of Laplacian waveforms as a generic method for identifying ERP generator patterns: I. Evaluation with auditory oddball tasks. Clin Neurophysiol 117:348-368. CrossRef Medline

Klein N, Sacher J, Geiss-Granadia T, Attarbaschi T, Mossaheb N, Lanzenberger R, Pötzi C, Holik A, Spindelegger C, Asenbaum S, Dudczak R, Tauscher J, Kasper S (2006) In vivo imaging of serotonin transporter occupancy by means of SPECT and $\left[{ }^{123} \mathrm{I}\right]$ ADAM in healthy subjects administered different doses of escitalopram or citalopram. Psychopharmacology (Berl) 188:263-272. CrossRef Medline

Liu Z, Zhou J, Li Y, Hu F, Lu Y, Ma M, Feng Q, Zhang JE, Wang D, Zeng J, Bao J, Kim JY, Chen ZF, El Mestikawy S, Luo M (2014) Dorsal raphe neurons signal reward through 5-HT and glutamate. Neuron 81:1360-1374. CrossRef Medline

Lotrich FE, Bies R, Muldoon MF, Manuck SB, Smith GS, Pollock BG (2004) Neuroendocrine response to intravenous citalopram in healthy control subjects: pharmacokinetic influences. Psychopharmacology (Berl) 178: 268-275. CrossRef Medline

Lucki I (1998) The spectrum of behaviors influenced by serotonin. Biol Psychiatry 44:151-162. CrossRef Medline
Maris E, Oostenveld R (2007) Nonparametric statistical testing of EEG- and MEG-data. J Neurosci Methods 164:177-190. CrossRef Medline

Markus CR, Firk C (2009) Differential effects of tri-allelic 5-HTTLPR polymorphisms in healthy subjects on mood and stress performance after tryptophan challenge. Neuropsychopharmacology 34:26672674. CrossRef Medline

Mathews TA, Fedele DE, Coppelli FM, Avila AM, Murphy DL, Andrews AM (2004) Gene dose-dependent alterations in extraneuronal serotonin but not dopamine in mice with reduced serotonin transporter expression. J Neurosci Methods 140:169-181. CrossRef Medline

Miyazaki KW, Miyazaki K, Doya K (2012b) Activation of dorsal raphe serotonin neurons is necessary for waiting for delayed rewards. J Neurosci 32:10451-10457. CrossRef Medline

Miyazaki KW, Miyazaki K, Tanaka KF, Yamanaka A, Takahashi A, Tabuchi S, Doya K (2014) Optogenetic activation of dorsal raphe serotonin neurons enhances patience for future rewards. Curr Biol 24:2033-2040. CrossRef Medline

Miyazaki K, Miyazaki KW, Doya K (2012a) The role of serotonin in the regulation of patience and impulsivity. Mol Neurobiol 45:213-224. CrossRef Medline

Murphy DL, Fox MA, Timpano KR, Moya PR, Ren-Patterson R, Andrews AM, Holmes A, Lesch KP, Wendland JR (2008) How the serotonin story is being rewritten by new gene-based discoveries principally related to SLC6A4, the serotonin transporter gene, which functions to influence all cellular serotonin systems. Neuropharmacology 55:932-960. CrossRef Medline

Murphy F, Smith K, Cowen P, Robbins T, Sahakian B (2002) The effects of tryptophan depletion on cognitive and affective processing in healthy volunteers. Psychopharmacology (Berl) 163:42-53. CrossRef Medline

Murthy NV, Selvaraj S, Cowen PJ, Bhagwagar Z, Riedel WJ, Peers P, Kennedy JL, Sahakian BJ, Laruelle MA, Rabiner EA, Grasby PM (2010) Serotonin transporter polymorphisms (SLC6A4 insertion/deletion and rs25531) do not affect the availability of 5-HTT to $\left[{ }^{11} \mathrm{C}\right] \mathrm{DASB}$ binding in the living human brain. Neuroimage 52:50-54. CrossRef Medline

Nakamura K, Matsumoto M, Hikosaka O (2008) Reward-dependent modulation of neuronal activity in the primate dorsal raphe nucleus. J Neurosci 28:5331-5343. CrossRef Medline

NCI-NHGRI Working Group on Replication in Association Studies, Chanock SJ, Manolio T, Boehnke M, Boerwinkle E, Hunter DJ, Thomas G, Hirschhorn JN, Abecasis G, Altshuler D, Bailey-Wilson JE, Brooks LD, Cardon LR, Daly M, Donnelly P, Fraumeni JF Jr, Freimer NB, Gerhard DS, Gunter C, Guttmacher AE, et al. (2007) Replicating genotypephenotype associations. Nature 447:655-660. CrossRef Medline

Olvet DM, Hatchwell E, Hajcak G (2010) Lack of association between the 5-HTTLPR and the error-related negativity (ERN). Biol Psychol 85:504508. CrossRef Medline

Palmer JA, Kreutz-Delgado K, Rao BD, Makeig S (2007) Modeling and estimation of dependent subspaces with non-radially symmetric and skewed densities. In: Proceedings of the 7th International Symposium on Independent Component Analysis (Davies ME, James CJ, Abdallah SA, Plumbley MD, eds.). New York: Springer.

Rabbitt PM (1966) Errors and error correction in choice-response tasks. J Exp Psychol 71:264-272. CrossRef Medline

Robinson OJ, Cools R, Sahakian BJ (2011) Tryptophan depletion disinhibits punishment but not reward prediction: implications for resilience. Psychopharmacology (Berl) 219:599-605. CrossRef Medline

Roiser JP, Blackwell AD, Cools R, Clark L, Rubinsztein DC, Robbins TW, Sahakian BJ (2006) Serotonin transporter polymorphism mediates vulnerability to loss of incentive motivation following acute tryptophan depletion. Neuropsychopharmacology 31:2264-2272. CrossRef Medline

Schinka JA, Busch RM, Robichaux-Keene N (2004) A meta-analysis of the association between the serotonin transporter gene polymorphism (5HTTLPR) and trait anxiety. Mol Psychiatry 9:197-202. CrossRef Medline

Selvaraj S, Turkheimer F, Rosso L, Faulkner P, Mouchlianitis E, Roiser JP, McGuire P, Cowen PJ, Howes O (2012) Measuring endogenous changes in serotonergic neurotransmission in humans: a $\left[{ }^{11} \mathrm{C}\right] \mathrm{CUMI}-101$ PET challenge study. Mol Psychiatry 17:1254-1260. CrossRef Medline

Siegert S, Herrojo Ruiz M, Brücke C, Huebl J, Schneider GH, Ullsperger M, Kühn AA (2014) Error signals in the subthalamic nucleus are related to post-error slowing in patients with Parkinson's disease. Cortex 60:103120. CrossRef Medline 
Soubrié P (1986) Reconciling the role of central serotonin neurons in human and animal behavior. Behav Brain Sci 9:319-335. CrossRef

Spielberger CD, Gorsuch RL, Lushene R (1970) The State-Trait Anxiety Inventory (STAI) test manual. Palo Alto, CA: Consulting Psychologists.

Steinhauser M, Yeung N (2010) Decision processes in human performance monitoring. J Neurosci 30:15643-15653. CrossRef Medline

Ullsperger M, Bylsma LM, Botvinick MM (2005) The conflict adaptation effect: It's not just priming. Cogn Affect Behav Neurosci 5:467-472. CrossRef Medline

Ullsperger M, Fischer AG, Nigbur R, Endrass T (2014) Neural mechanisms and temporal dynamics of performance monitoring. Trends Cogn Sci 18:259-267. CrossRef Medline

Veenstra-VanderWeele J, Anderson GM, Cook EH Jr (2000) Pharmacogenetics and the serotonin system: initial studies and future directions. Eur J Pharmacol 410:165-181. CrossRef Medline
Verguts T, Notebaert W, Kunde W, Wühr P (2011) Post-conflict slowing: cognitive adaptation after conflict processing. Psychon Bull Rev 18:76-82. CrossRef Medline

Wendland JR, Moya PR, Kruse MR, Ren-Patterson RF, Jensen CL, Timpano KR, Murphy DL (2008) A novel, putative gain-of-function haplotype at SLC6A4 associates with obsessive-compulsive disorder. Hum Mol Genet 17:717-723. CrossRef Medline

Wessel JR, Ullsperger M (2011) Selection of independent components representing event-related brain potentials: a data-driven approach for greater objectivity. Neuroimage 54:2105-2115. CrossRef Medline

Winstanley CA (2011) The utility of rat models of impulsivity in developing pharmacotherapies for impulse control disorders. Br J Pharmacol 164: 1301-1321. CrossRef Medline

Xiang Z, Wang L, Kitai ST (2005) Modulation of spontaneous firing in rat subthalamic neurons by 5-HT receptor subtypes. J Neurophysiol 93: 1145-1157. Medline 